\title{
UNUSUAL PRESENTATION OF EXTENSIVE HYDATID CYST IN CALF MUSCLE: A CASE REPORT
}

Dinesh Kumar Agrawal1, Swish Kumar Singh², Suganita³, G. N. Singh4, Amar Kumar Singh

${ }_{1}^{1}$ Post Graduate, Department of Radiodiagnosis, Patna Medical College \& Hospital, Patna.

${ }^{2}$ Post Graduate, Department of Radiodiagnosis, Patna Medical College \& Hospital, Patna.

${ }^{3}$ Post Graduate, Department of Dermatology, Venereology \& Leprology, Patna Medical College \& Hospital, Patna.

${ }^{4}$ Professor \& HOD, Department of Radiodiagnosis, Patna Medical College \& Hospital, Patna.

${ }^{5}$ Assistant Professor, Department of Radiodiagnosis, Patna Medical College \& Hospital, Patna.

\section{ABSTRACT}

Cystic echinococcosis also called as hydatidosis is the larval cystic stage of a tapeworm (Echinococcus Granulosus) that may cause illness in humans (Intermediate host) and can involve any organ including the liver, lung, heart, brain, kidneys and long bones. Primary or exclusive involvement of muscle is extremely rare and these are usually secondary in nature.[1],[2] We are presenting here an extremely unusual and rare case of extensive primary intramuscular (Right calf muscle) hydatid cyst found in popliteal fossa and lower leg of a 65-year-old women who presents with enlarging swelling of right calf for 15 years and pain for 7 days. The patient was sent to the Radiology Department for further investigations and the presence of hydatidosis was confirmed on routine ultrasound followed by computed tomography and magnetic resonance imaging and was further verified by histopathology. Hydatidosis should always be included as the differential of an unusual muscular mass in the endemic regions. Few of the earlier reported cases of primary intramuscular (Calf muscle) hydatid have localised involvement of calf muscle by one or few cysts. Our case is unusual and unique, as there is extensive involvement of calf muscle by multiple hydatid cysts.

\section{KEYWORDS}

Hydatid Cyst, USG, CT, MRI.

HOW TO CITE THIS ARTICLE: Agrawal DK, Singh SK, Suganita, et al. Unusual presentation of extensive hydatid cyst in calf muscle: a case report. J Evolution Med Dent Sci 2016;5(6):325-329, DOI: 10.14260/jemds/2016/70

\section{INTRODUCTION}

Hydatid disease is a parasitic disease of tapeworm of the echinococcus type. The most common forms found in humans are cystic and alveolar echinococcosis caused by echinococcus granulosus and multilocularis respectively.[1]

Humans are accidental hosts and get infected by ingestion of embryonated eggs, which then hatches in the small intestine and releases an oncosphere that moves to the circulatory system by penetrating small intestine wall and gets lodged in different organs, in particular liver and lungs. The oncosphere then develops into a cyst, which slowly enlarges creating protoscolices and daughter cysts within the cyst.

Primary involvement of muscle is extremely uncommon even in endemic regions. ${ }^{[2]}$ We describe a patient with an enlarging mass in popliteal fossa for 15 years and was found to have hydatid disease.

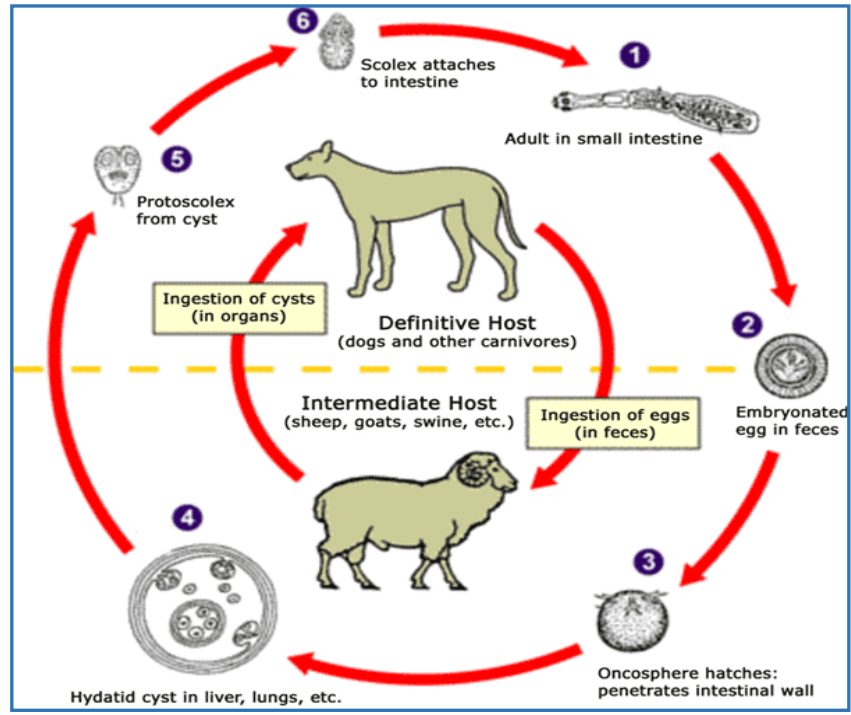

\section{ECHINOCOCCUS LIFE CYCLE}

\section{CASE REPORT}

A 65-year-old women presented with enlarging swelling of right calf for 15 years and pain in right lower limb for 7 days.

There was no history of diabetes, hypertension, tuberculosis and jaundice.

There was history of some previous operation 4 years back for which no papers were available.

On local examination, there was swelling of right calf region. Veins are prominent over swelling and surface looks nodular.

On palpation swelling contains multiple clumps of variable sizes, which are firm in consistency and not fixed to skin. 
It is non-tender and movements of knee and ankle are within normal limits.

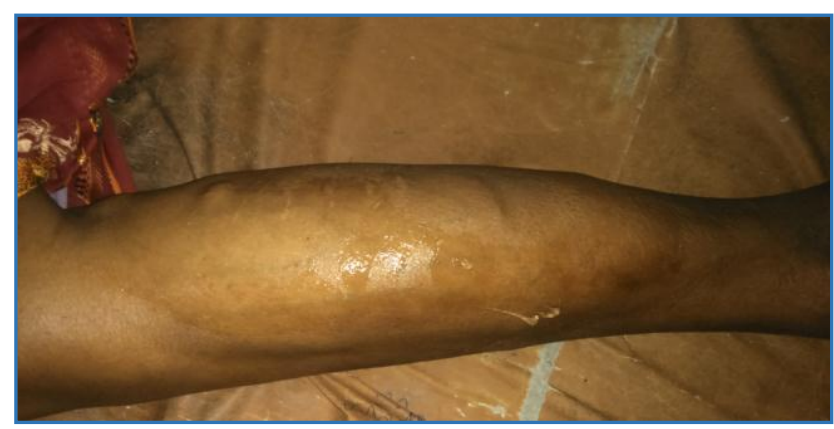

Fig. 1: Image of the affected right limb

Routine haematological and biochemical investigations were within normal limits. As a part of diagnostic protocol radiograph of the right lower limb was performed followed by ultrasound, 16 slice non-contrast computed tomography scan and $1.5 \mathrm{~T}$ magnetic resonance imaging.

\section{IMAGING FINDINGS}

Radiograph - Large soft tissue swelling with multiple round to oval shaped structures within it are seen predominantly on posterior-medial aspect of right lower leg. No calcification seen and the underlying bones appears normal.

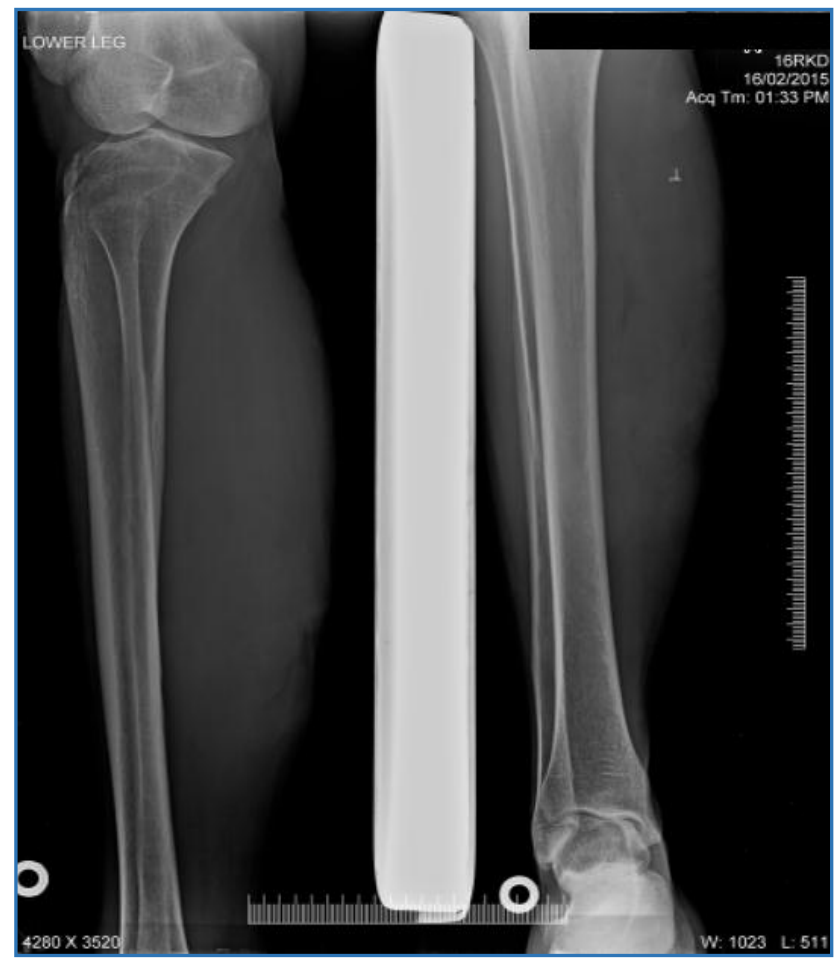

Fig. 2: Plain radiograph showing large lobulated soft tissue swelling with round to oval shaped structures within it

Ultrasonography (Gray Scale and Colour Doppler)

Extensive multivesicular cystic lesions with multiples of well defined, round daughter cysts within it are seen in the calf involving soleus and medial head of gastrocnemius.

These lesions are also extending into and involving the subcutaneous plane.

On Doppler study, no colour uptake is seen within them. Ultrasound scan of whole abdomen are within normal limits.

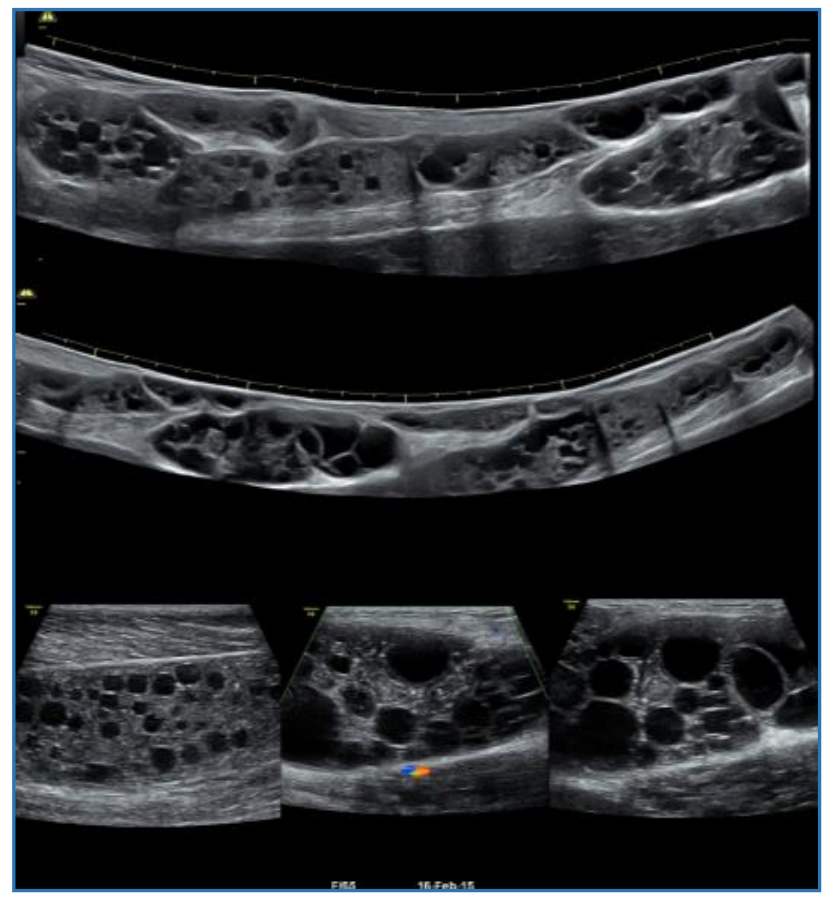

Fig. 3: USG image showing extensive intramuscular and subcutaneous cysts with multiple daughter cysts within it

\section{Non-Contrast Computed Tomography}

Multiple large hypodense cystic lesions containing multiple round hypodense cystic lesions with hyperdense walls are seen involving the right calf muscle predominantly soleus and medial head of gastrocnemius. These lesions are also seen in the subcutaneous plane on medial and posterior aspect of calf. No cyst wall calcification seen.
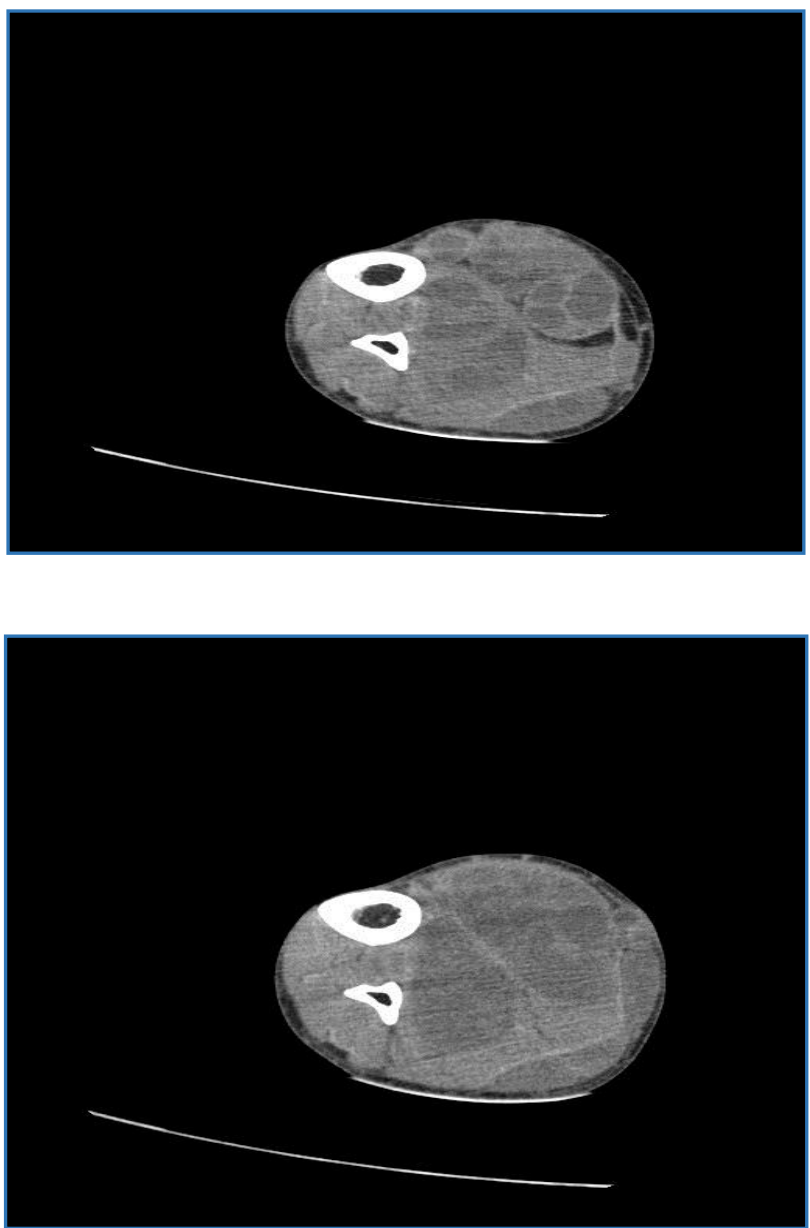

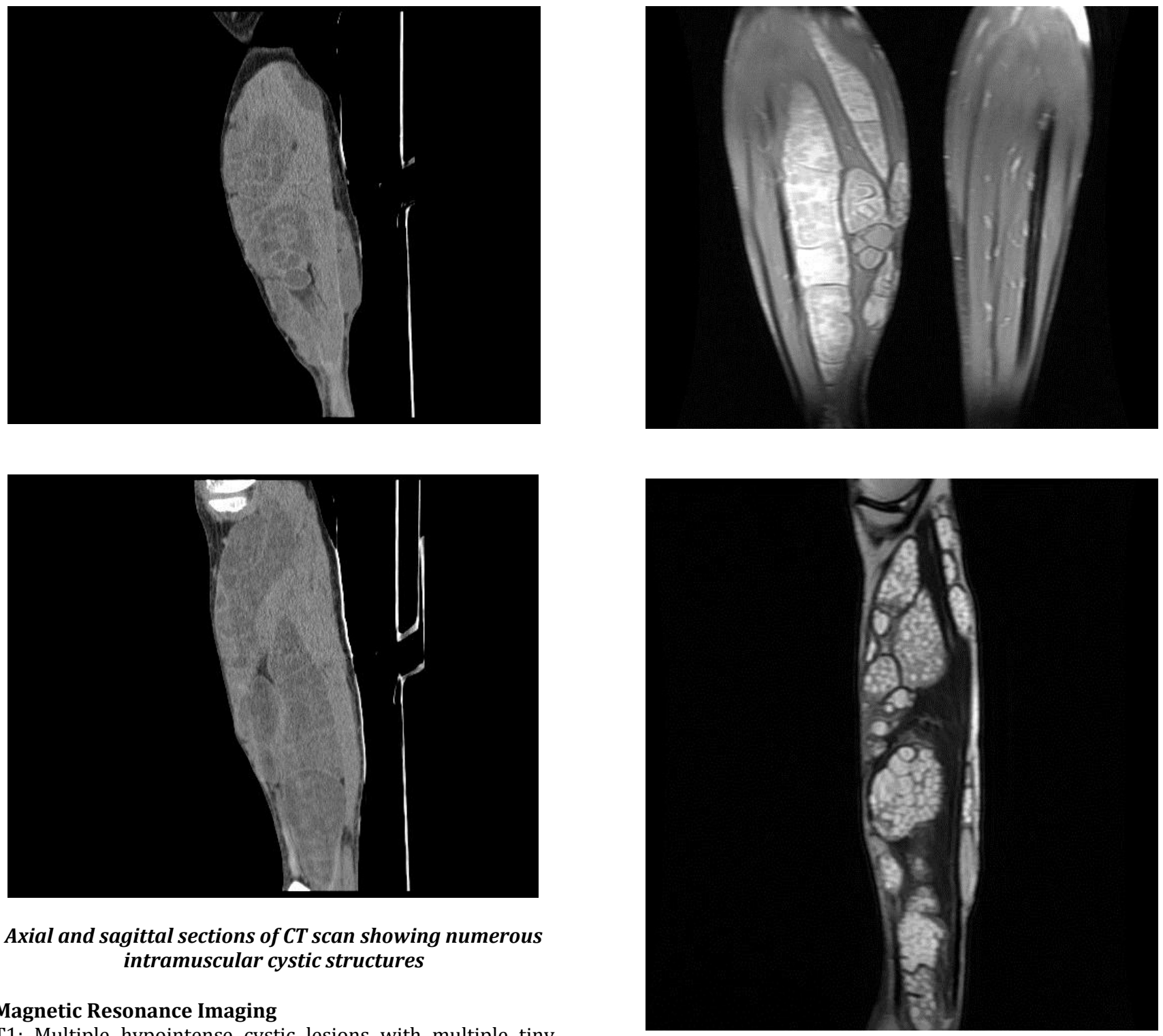

\section{Magnetic Resonance Imaging}

T1: Multiple hypointense cystic lesions with multiple tiny round hypodensities, within it are seen extensively in the calf and lower leg region predominantly in posterior-medial aspect involving both muscular and subcutaneous plane.

T2:Multilocular hyperintense cystic lesions with a low intensity rim are seen.
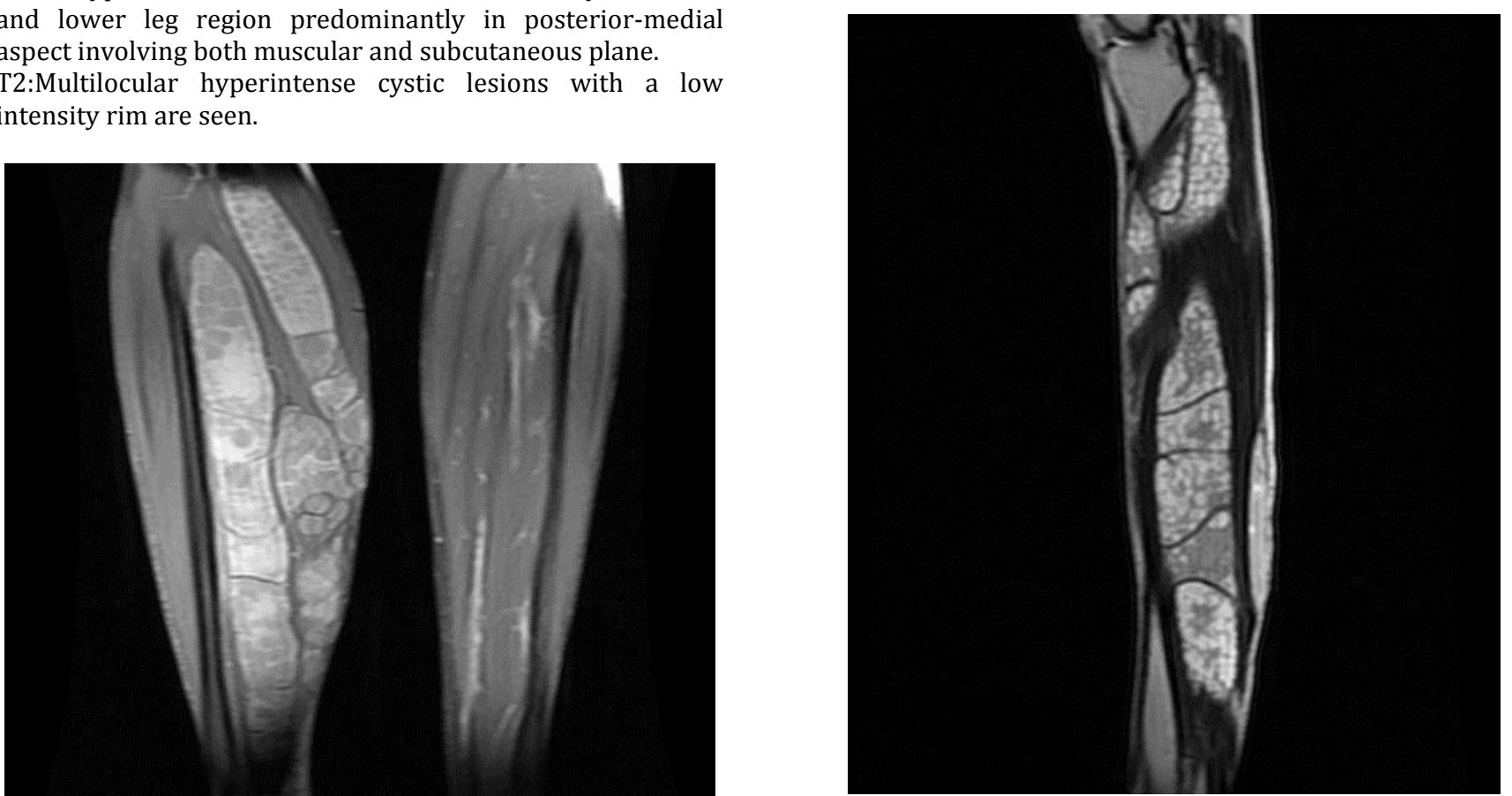

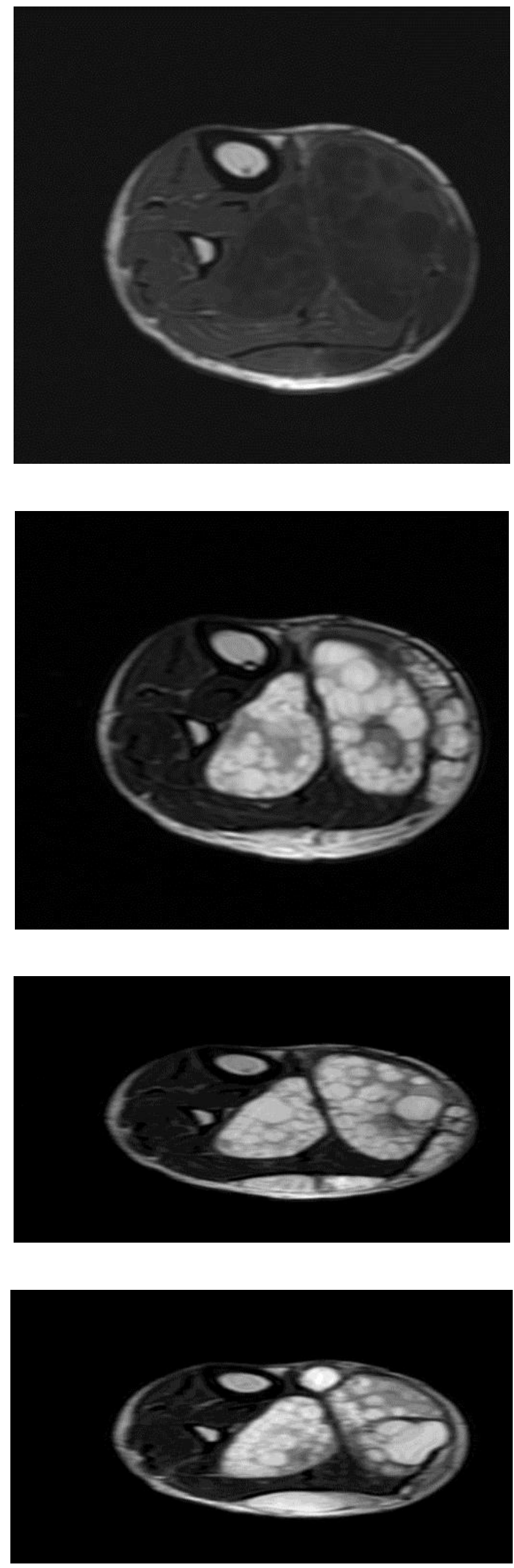

Proton Density MRI, Sagittal

\section{DISCUSSION}

The usual sites of hydatidosis is liver followed by lung and muscle involvement is usually secondary in nature. Primary intramuscular hydatid is extremely uncommon and rare.[3][4] Some of the factors responsible for it includes hepatic and pulmonary barriers, muscle contractibility and the presence of lactic acid in muscles which inhibit the growth of cysts.

Most of the reported cases of intramuscular hydatidosis includes quadriceps.[5] biceps.[6] gluteus.[6] trapezius.[7] psoas.[8] biceps femoris.[9] triceps.[10] and very cases of gastrocnemius. ${ }^{[10]}$ and soleus. There are also very few reported cases of primary subcutaneous hydatidosis in lower limb.[10] The predominant localisation in the proximal muscles of lower limbs may be due to large volume of muscle mass and its rich blood supply.

The preoperative diagnosis of hydatid disease is very important as to limit the risk of anaphylactic shock and dissemination of rotoscoliosis during surgery, if the cyst is accidentally opened or ruptured.

Ultrasound is the first line diagnostic tool of choice as it can detect daughter cysts, floating membranes and hydatid sands. It is also used for staging and classification of hydatid cyst.

Computed tomography is best for detecting cyst wall calcification.

Magnetic resonance imaging is best for detecting the nature and extensions of cysts, any cyst wall defects or any associated complications or underlying abnormality.

Serological tests usually play a complimentary for primary diagnosis.[11]

The treatment of choice for intramuscular hydatid is complete surgical excision of intact cyst and surrounding tissue. Medical treatment includes anti-helminthic drugs, such as albendazole or praziquantel for disseminated, inaccessible hydatids and also spillage of hydatid during intervention leading to recurrence.[12]

In conclusion primary intramuscular hydatidosis is extremely unusual and can cause delay or difficulty in diagnosis, especially in the absence of typical and characteristic radiological features. The possibility of hydatid disease should always be in the differential of an unusual cystic intramuscular mass, especially in endemic regions and appropriate radiological investigations should be sought to establish the diagnosis preoperatively.

\section{REFERENCES}

1. Eckert J, Deplazes P. Biological, epidemiological and clinical aspects of echinococcosis, a zoonosis of increasing concern. Clin Microbiol Rev 2004;17:107-35. [PMC free article] [PubMed]

2. García-Alvarez F, Torcal J, Salinas JC, et al. Musculoskeletal hydatid disease: a report of 13 cases. Acta Orthop Scand 2002;73:227-31. [PubMed]

3. Sinhasan SP, Palachandra A. Primary intramuscular hydatid cyst: A rare case report. Ann Trop Med Public Health [serial online] 2012 [cited 2016 Jan 5]; 5:546-8. Available

from: http://www.atmph.org/text.asp?2012/5/5/546/ 105161.

4. Martin J, Marco V, Zidan A, et al. Hydatid disease of the soft tissues of the lower limb: findings in three cases. Skeletal Radiol 1993; 22:511-4. [PubMed] 
5. Ozkoç G, Akpinar S, Hersekli MA, et al. Primary hydatid disease of the quadriceps muscle: a rare localization. Arch Orthop Trauma Surg. 2003;123:314-6. [PubMed]

6. Ates M, Karakaplan M. Hydatid cyst in the biceps and gluteus muscles: Case report. Surg Infect (Larchmt) 2007;8:475-8. [PubMed]

7. Calò PG, Tatti A, Tuveri M, et al. Hydatid cyst of trapezius muscle: An unusual localisation. Report of a case and review of the literature. Chir Ital 2007;59:873-6. [PubMed]

8. Bilanoviæ D, Zdravkoviæ D, Randjeloviæ T, et al. Lesion of the femoral nerve caused by a hydatid cyst of the right psoas muscle. Srp Arh Celok Lek 2010; 138:502-5. [PubMed]
9. Hamdi MF, Touati B, Abid A. Primary hydatid cyst of the biceps femoris. Musculoskelet Surg. 2010;94:59-61. [PubMed]

10. Gougoulias NE, Varitimidis SE, Bargiotas KA, et al. Skeletal muscle hydatid cysts presenting as soft tissue masses. Hippokratia. 2010;14:126-30. [PMC free article] [PubMed]

11. Zhang W, Li J, McManus DP. Concepts in immunology and diagnosis of hydatid disease. Clin Microbiol Rev 2003;16:18-36. [PMC free article] [PubMed]

12. Guidelines for treatment of cystic and alveolar echinococcosis in humans. WHO Informal Working Group on Echinococcosis. Bull World Health Organ. 1996;74:23142. [PMC free article][PubMed] 